greater precision than the few $\mathrm{I}$ had noted in November. The new radiant in Sextans, I now deduce at R. A. $148^{\circ}$, Decl. $2^{\circ}$ N., and that at $\tau$ Leonis, as near Crater R.A. $165^{\circ}$, Decl. $6^{\circ} \mathrm{S}$. The meteors from these new sinowers are very rapid and white, usually leaving bright streaks for 2 or 3 secs. in their path.

Ashley Down, Bristol, January 2 W. F. DENing

\section{ALEXANDER BAIN}

$\mathrm{T} \mathrm{T}$ is with much regret that we announce the death of Mr. Alexander Bain, which took place at Glasgow on January 2. To many of our readers his name is perhaps unknown, and yet the inventions of $\mathrm{Mr}$. Bain, made when telegraphy was in its infancy, were of the very highest importance. They were perhaps made too soon. Mr. Bain himself never reaped the benefit of them, and would have died in great poverty had it not been for a pension of $80 l$. a year obtained for him from Mr. Gladstone chiefly through the exertions of Mr. C. W. Siemens, Sir William Thomson, and the Society of Telegraph Engineers.

One of the most important services of Mr. Bain to telegraphy was the reinvention of the method of making use of "bodies of natural waters" "to complete the electric circuit by laying a single insulated wire between the given stations, having at each end a metallic brush immersed in the water." In 1838 Steinheil discovered the use of the earth for completing a circuit instead of a return wire, but does not appear to have taken steps to bring his discovery into notice, or to remove the prejudices with which a discovery so startling would naturally be met. Mr. Bain seems to have established the principle for himself, and he published it in a patent of $184 \mathrm{I}$, by Wright and Bain, for "Improvements in applying electricity to control railway engines and carriages, to mark time, to give signals, and to print intelligence ${ }_{i}^{*}$ at different places." It is impossible to say how large a part of the completeness of our present telegraphic system, particularly of our submarine telegraphic system, is due to this great discovery of Steinheil and Bain.

An early invention by Mr. Bain, was that of the electrochemical telegraph. This was patented in 1846 . Paper chemically prepared is drawn under a metallic style which rubs upon it. As long as there is no current passing in the line the paper comes away from the style unmarked, but each signal sent through the line passes by the style to the prepared paper and leaves a mark. Combinations of dots and dashes, as in the Morse system, formed Mr. Bain's alphabet.

At first the signals were sent by hand by a simple contact key, but Mr. Bain soon found his system capable of receiving signals at far higher speed than that of the fastest hand sending. He was thus led to the invention of automatic methods of transmitting signals of which one is the basis of the most important method at present in use. A slip of paper is perforated with holes arranged in groups, forming the letters required in accordance with the code of signals. 'This slip is passed between a metallic roller and a contact point. As long as the contact point is separated from the roller by the paper slip, no current passes in the line. But when one of the perforated holes comes under the contact point, the point falls in and makes contact with the metallic roller. The circuit is titus closed, and a signal is sent.

This apparatus was tried before Committees of the In stitute and of the Legislative Assembly at Paris. Through a line between Paris and Lilie, a message of 282 words was sent. The time taken was fifty-two seconds! The fastest automatic receiving by mechanical instruments of the most refined modern construction, such, for example, as the instruments of Wheatstone, does not commonly reach 100 words per minute. We hear from Sir William Thomson, in his recent address to the British Association, that he saw in America "Edison's Automatic Tele- graph delivering $x, 057$ words in 57 seconds-this done by the electro-chemical method of Bain." That Mr. Bain's method was not received in England cannot but be regarded as a great misfortune.

These were, perhaps, Mr. Bain's principal inventions, but there are others of such importance that they well deserve notice. Several of his patents relate to the keeping of time by clocks controlled or driven electrically bv a standard clock. Jones' system, now so Jargely used in England, is based upon the system of Bain. He invented the earth battery in 1843 , or rather reinvented it, as Gauss and Steinheil had previously obtained a current, after the discovery by Steinheil of using the earth for a return wire, making one of the earth plates of zinc and the other of copper. In 1844 he patented ingenious apparatus for registering the progress of ships and for taking soundings. Vanes caused to rotate by the motion of the "log" or "sounding fly," through the water were employed, and an electrical method of observing the result on board was employed. The same patent describes apparatus for giving warning when the temperature of the hold of a ship rises above a certain point. An electric circuit was employed, which was closed by the expansion by heat of mercury contained in a tube. The current passing in the circuit traversed coils which formed an electro-magnet. A pointer or alarm connected with the magnet gave the required warning. This method is now very commonly employed for fire alarms; and modifications of it have been proposed for giving warning of over-heating in the bearings of machinery.

He had also an electric method of playing a keyed instrument at a distance on more than one organ or piano at a time; and he applied his perforated. paper to the automatic playing of a wind instrument, such as an organ. For this purpose the paper, properly punched, was drawn between the openings of the wind chest and the openings of the notes to be played upon. Whenever and as long as there was a punched hole of the paper between the wind chest and the pipe the note of the pipe scunded. When there was a blank space beiween the wind chest and pipe the pipe was silent.

In his later years Mr. Bain's inventions have been inconsiderable. Some years ago he was stricken down with paralysis. He died at the age of sixty-six, on the second day of this year, in the Home for Incurables, Broomhill, near Glasgow.

\section{PHOTOGR APHS OF THE SPECTRA OF VENUS AND a LYRE}

GINCE the spring of I872 I have been making photographs of the spectra of the stars, planets, and moon, and particularly among the stars, of $a$ Lyra and a Aquila, with my 28 -inch refiector and 12 -inch refractor. In the photograph of $a$ Lyræ, bands or broad lines are visible in the violet and ultra-violet region, unlike anything in the solar spectrum. The research is difficult, and consumes time, because long exposures are necessary to impress the sensitive plate, and the atmosphere is rarely in the best condition. The image of a star or planet must be lsept motionless for from ten to twenty minutes, and hence the driving-clock of the telescope is severely taxed.

During last summer I obtained some good results, and in October took photographs of the spectrum of Venus, which show a large number of lines. I am now studying these pictures, and have submitted them to the inspection of several of my scientific friends, among others, Professors Barker Langley, Morton, and Siliman. There seems to be in the case of Venus a weakening of the spectrum towards $E$ and above that line of the same character as that I have photographically observed to take place in the spectrum of the sun near sunset.

New York, December, 1876 